\title{
HETEROTOPIC OSSIFICATION AFTER SPINAL CORD INJURY EPIDEMIOLOGY AND RISK FACTORS
}

\author{
R. H. WITTENBERG, U. PESCHKE, U. BÖTEL
}

From Bergmannsheil Hospital, Bochum, Germany

\begin{abstract}
From 1981 to 1986 we treated 413 patients for acute spinal-cord injuries. We reviewed 356 patients followed for a minimum of two years of whom $71(20 \%)$ developed heterotopic ossification around one or more joints.

Heterotopic ossification occurred more often in male patients (23\%) than in female (10\%), and was most frequent in the 20- to 30-year age group. It was also more common after injuries of the lower cervical or thoracic spine than after those of the lumbar spine. Patients with severe neurological deficits (Frankel grades $A$ and B) showed significantly more heterotopic ossification but there was no correlation with the number or severity of associated head and limb injuries. Serum calcium levels did not change significantly in either group for 30 weeks after injury, but the erythrocyte sedimentation rate and the alkaline phosphatase level were significantly increased at six weeks in patients with heterotopic ossification.
\end{abstract}

Heterotopic ossification is an important complication of head and spinal-cord injuries, producing metaplastic formation of new bone in connective tissues and muscles surrounding joints (Heller and Ringe 1979). Its reported incidence varies from $1 \%$ to $50 \%$ (Dejerine and Ceillier 1918; Coddington 1961; Guttmann 1976). It most commonly affects the large proximal joints (Heller and Ringe 1979; Henderson and Reid 1981) and its aetiology is not yet known. Possible factors include local microtrauma, disturbance of calcitonin and parathormone levels, and genetic disposition (Chantraine and Minaire 1981). Decreased blood flow and changes in $\mathrm{pH}$ may also be important (Bassett 1962; Nechwatal 1972).

We have studied the incidence of heterotopic ossification in patients with traumatic paraplegia and tetraplegia in an attempt to detect predisposing factors and define risk factors.

\section{PATIENTS AND METHODS}

From 1981 to 1986 we treated 413 patients for acute spinal-cord injuries in the Bergmannsheil Hospital in Bochum. The complete clinical records and radiographs

R. H. Wittenberg, MD, Associate Professor

Ruhr University Clinic, St Josef Hospital, Gudrunstrasse 56, 4630 Bochum, Germany.

U. Peschke, MD, Anaesthesiologist

Elizabeth Kranken Haus, Hockstrasse 39, 5860 Iserlohn, Germany.

U. Bötel, MD, Head of Unit

Spinal Cord Injury Unit, Bergmannsheil Hospital Bochum, Gilsingstrasse 14, 4630 Bochum, Germany.

Correspondence should be sent to Dr R. H. Wittenberg.

(C) 1992 British Editorial Society of Bone and Joint Surgery $0301-620 \mathrm{X} / 92 / 2313 \$ 2.00$

J Bone Joint Surg [Br] 1992; 74-B:215-8. of 356 patients followed up for a minimum of two years after injury were evaluated with regard to 28 variables.

Mean and standard deviation were calculated and statistical analysis performed according to the StudentNewman-Keul test or the paired Student's $t$-test for paired values.

\section{RESULTS}

There were 274 male and 82 female patients. Heterotopic ossification (HO) developed in $71(20 \%) ; 23 \%$ of the male patients and $10 \%$ of the females developed HO (Fig. 1). The mean age of all patients was 35.4 years; 35.8 years in those without $\mathrm{HO}$ and 33.8 years in those with $\mathrm{HO}$. There was a significantly higher incidence $(29 \%)$ in patients between 20 and 30 years of age than in the other age groups.

In all, 127 patients had tetraplegia and 207 paraplegia; 22 had only a deficit of sensation. None of the last group developed $\mathrm{HO}$, while $24 \%$ of the tetraplegic and $19 \%$ of the paraplegic patients did. In the group with $\mathrm{HO}$, the spinal injuries were most commonly at C5 $(24 \%)$ and C6 $(18 \%)$ levels. Thoracic lesions were found at D5 $(11 \%)$, D6 $(10 \%)$, and D12 $(15 \%)$. By contrast, in patients without $\mathrm{HO}$ the most common injury level was at $\mathrm{L} 1$ $(26 \%)$ with fewer cervical and thoracic injuries: C5 $(13 \%)$, C6 (11\%), D5 (2\%) and D6 (4\%). Injury at D12 was about the same in both groups $(12 \%)$.

However, the patients with heterotopic ossification showed a significantly $(p<0.05)$ higher proportion of Frankel A and B injuries (no useful motor function) than patients without such changes (Table I). In those without $\mathrm{HO}, 63.5 \%$ had no concomitant injuries as compared with $47.9 \%$ of patients with HO. In the group without 


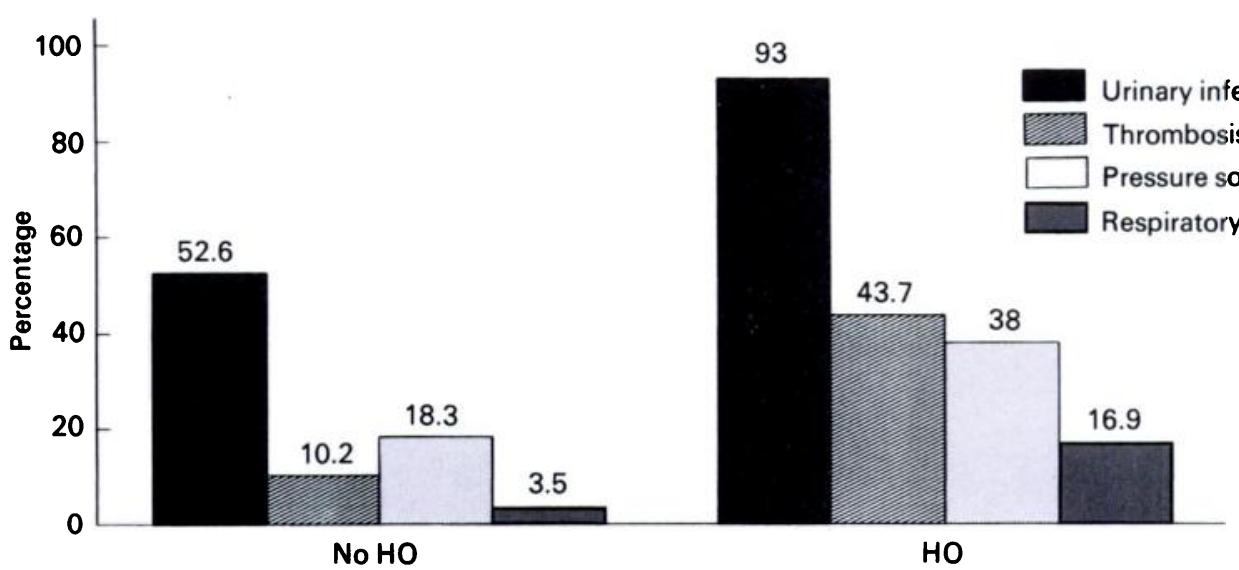

Fig. 1

Complications during time in hospital in patients with (HO) and without heterotopic ossification (No HO). Urinary tract infections, thrombosis, pressure sores and respiratory disease were all significantly more frequent in patients with HO.

Table I. Frankel grading of patients with and without heterotopic ossification on the day of injury and at discharge from hospital

\begin{tabular}{lccccc}
\hline \multirow{2}{*}{$\begin{array}{l}\text { Frankel } \\
\text { grade }\end{array}$} & \multicolumn{2}{l}{ Injury } & & \multicolumn{2}{l}{ Discharge } \\
\cline { 6 - 6 } \cline { 5 - 6 } Nith $H O$ & Number & Per cent & & Number & Per cent \\
A & 41 & 59.4 & 35 & 50.7 \\
B & 13 & 18.9 & 13 & 18.9 \\
C & 14 & 20.3 & 16 & 23.2 \\
D & 1 & 1.4 & 5 & 7.2 \\
E & 0 & 0 & 0 & 0 \\
Without & $H O$ & & & \\
A & 53 & 22.9 & 46 & 19.9 \\
B & 28 & 12.2 & 21 & 9.1 \\
C & 75 & 32.4 & 27 & 11.7 \\
D & 62 & 26.8 & 108 & 46.7 \\
E & 13 & 5.7 & 29 & 12.6 \\
\hline
\end{tabular}

Table II. Number and incidence of associated injuries in patients with and without heterotopic ossification

\begin{tabular}{|c|c|c|c|c|}
\hline \multirow[b]{2}{*}{ Site of injury } & \multicolumn{2}{|c|}{ Without HO } & \multicolumn{2}{|c|}{ With HO } \\
\hline & Number & Per cent & Number & Per cent \\
\hline \multirow[t]{3}{*}{ Cranial } & 42 & 14.7 & 12 & 16.9 \\
\hline & 16 & 5.6 & 4 & 5.6 \\
\hline & 20 & 7.0 & 7 & 9.9 \\
\hline Thoracic & 65 & 22.8 & 29 & 40.9 \\
\hline Abdominal & 14 & 4.9 & 4 & 5.6 \\
\hline Upper extremity & 21 & 7.3 & 8 & 11.3 \\
\hline Lower extremity & 37 & 13.0 & 11 & 15.5 \\
\hline Pelvis & 13 & 4.6 & 1 & 1.4 \\
\hline
\end{tabular}

*Cranial I: contusion without amnesia; II : contusion with amnesia; III : organic brain damage

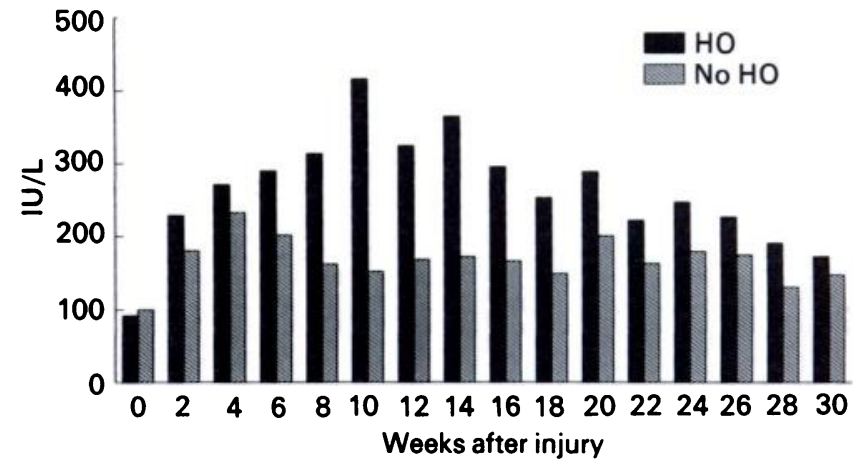

Fig. 2

Serum alkaline phosphatase levels in patients with (HO) and without heterotopic ossification (No HO) after injury.

Table III. Number and incidence of concomitant disease before injury in patients with and without heterotopic ossification

\begin{tabular}{llllll}
\hline & \multicolumn{2}{l}{ Without HO } & & \multicolumn{2}{c}{ With HO } \\
\cline { 2 - 3 } \cline { 5 - 6 } Disease & Number & Per cent & & Number & Per cent \\
\hline Cardiovascular & 37 & 13.0 & & 5 & 7.0 \\
Gastro-intestinal & 13 & 4.6 & & 3 & 4.2 \\
Respiratory & 11 & 3.9 & & 1 & 1.4 \\
Urogenital & 14 & 4.9 & & 5 & 7.0 \\
Metabolic & 9 & 3.2 & & 2 & 2.8 \\
Spinal & 24 & 8.4 & & 10 & 14.1 \\
Dermal & 4 & 1.4 & & 0 & 0 \\
Neurological & 17 & 6.0 & & 3 & 4.2 \\
Psychotic & 18 & 6.3 & & 2 & 2.8 \\
$\begin{array}{l}\text { Alcoholism/drug } \\
\text { dependency }\end{array}$ & 11 & 4.9 & & 3 & 4.2 \\
Sensory organs & 7 & 2.5 & 3 & 4.2 \\
Undefined & 7 & 2.5 & 0 & 0 \\
\hline
\end{tabular}




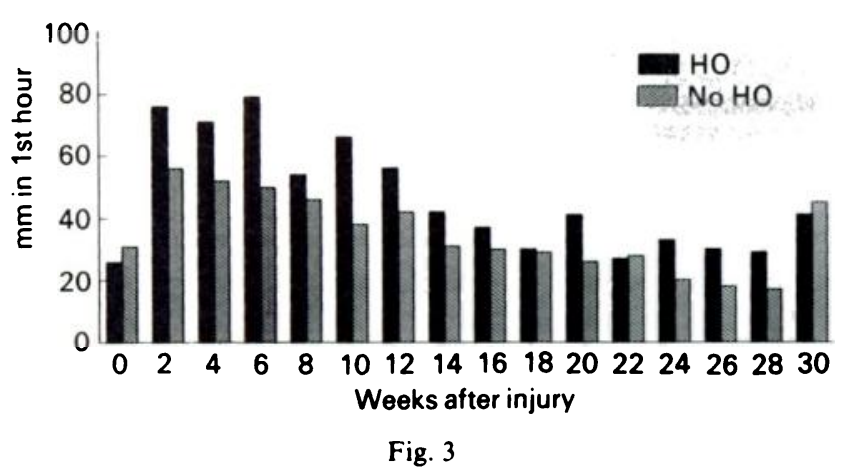

Erythrocyte sedimentation rate in patients with (HO) and without heterotopic ossification (No HO) after injury.

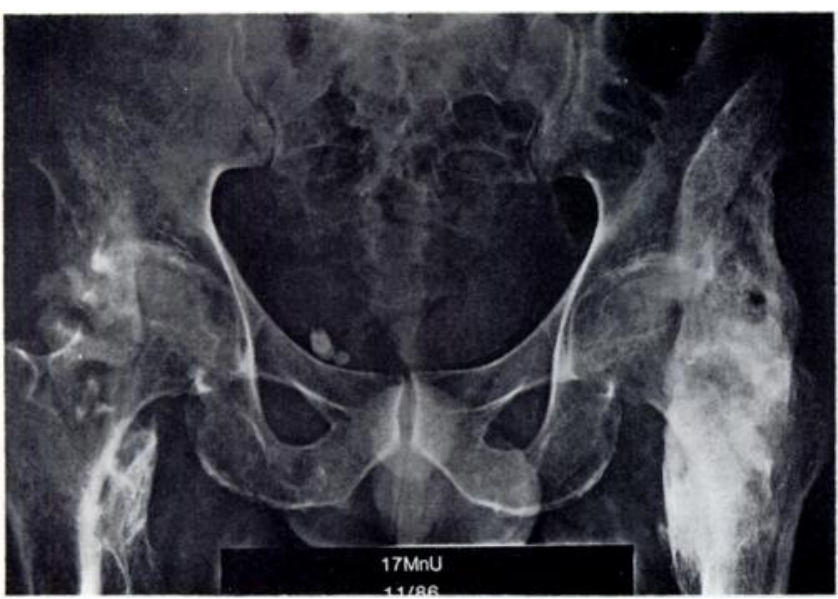

Fig. 4

Radiograph of both hips of a 37-year-old man 17 months after paraplegia. The left hip is completely ankylosed and the right hip has moderate restriction of movement.

HO, $27.3 \%$ of the patients also had a cranial injury; in the HO group $32.4 \%$ had injuries to the brain (Table II). Of the patients with $\mathrm{HO}, 31 \%$ had one, $5.6 \%$ two and $1.4 \%$ three concomitant diseases before injury, while in the group without $\mathrm{HO} 39 \%$ had one concomitant disease, $8.2 \%$ had two, $3.2 \%$ three, $1.8 \%$ had four and $0.7 \%$ five concomitant diseases. Patients without HO had a significantly higher percentage of cardiovascular disease $(p<0.05)$, while HO patients had a higher incidence of spinal problems before the injury (Table III).

Patients with spinal injuries may develop complications such as urinary tract infection, thrombo-embolism, pressure sores and respiratory disease. The number and the severity of these complications were higher in those with heterotopic ossification (Fig. 1).

Serum alkaline phosphatase levels increased in both groups from about $100 \mathrm{U} / 1$ at admission to more than $200 \mathrm{U} / 1$ at four weeks. After six weeks this increase was significantly greater in the patients with $\mathrm{HO}$; it was greatest after ten weeks and continued at a significantly increased level up to 20 weeks after the initial injury (Fig. 2). Over the same time period, serum calcium increased from $4.2 \mathrm{mmol} / 1$ to only $4.6 \mathrm{mmol} / \mathrm{l}$ after ten weeks, and there was never a significant difference in levels between the two groups. The erythrocyte sedimentation rate after one and two hours increased significantly $(p<0.05)$ from the day of injury to two weeks after injury. In the patients with $\mathrm{HO}$ it reached a maximum after six weeks of about $80 \mathrm{~mm}$ for the first hour and $110 \mathrm{~mm}$ for the second hour (Fig. 3).

New bone formation around only one joint was seen in $45.1 \%$ of the 71 patients with HO. Two joints were involved in $29.6 \%$, three in $9.9 \%$ and four in $12.6 \%$. There were five and 11 affected joints in the other two patients. The joints most often involved were the left hip (70.4\%) and the right hip (57.8\%). In 12 hips (13.2\%) there was complete ankylosis in slight flexion (Fig. 4). Five elbows developed complete ankylosis in $60^{\circ}$ to $100^{\circ}$ flexion. Two knees became completely ankylosed.

\section{DISCUSSION}

The $20 \%$ incidence of heterotopic ossification in our series of patients with spinal-cord injuries is within the range of $1 \%$ to $50 \%$ that has been previously reported (Dejerine and Ceillier 1918; Coddington 1961; Wharton and Morgan 1970; Guttmann 1976). The localisation of the changes and the incidence of loss of movement also correlate with other reported series (Damanski 1961; Orzel and Rudd 1985) as does the percentage of ankylosis (Hardy and Dickson 1963; Wharton and Morgan 1970; Knudsen, Lundberg and Ericsson 1982; Garland et al 1983).

We found twice the incidence of $\mathrm{HO}$ in males $(23 \%)$ than in females $(10 \%)$. This may be explained by the hypothesis that $\mathrm{HO}$ is influenced by increased mobilisation of calcium from the skeleton, secondary to immobility, osteoporosis and venous stasis (Wharton 1975; Major, Resnick and Greenway 1980; Chantraine and Minaire 1981). However, this theory was not supported by the blood calcium levels: they did not increase significantly over 30 weeks and were no different in patients with or without HO.

There were more patients with mid-thoracic and cervical spine lesions in the group with $\mathrm{HO}$, and more with Frankel grades A and B. This correlates with other reports that $\mathrm{HO}$ developed more often in patients with complete lesions (Scher 1976; Hernandez et al 1978; Chantraine and Minaire 1981; Knudsen et al 1982). We found no correlation with the fracture type or its treatment by surgical or conservative methods, or with the incidence of associated head injuries, although it is known that patients with cranial injuries alone may also develop HO. Couvée in 1971 reported 12 severe cases of HO requiring excision; in six of these patients a cerebral injury was the cause. Henderson and Reid (1981) found HO of the hand in one patient after severe head injury and coma and one after spinal-cord injury.

The only significant difference found was a higher incidence of thoracic injuries in the $\mathrm{HO}$ group. The 
R. H. WITTENBERG, U. PESCHKE, U. BÖTEL

theory that previous trauma to an extremity may predispose to the development of $\mathrm{HO}$ is not supported by our study. We also found no significant difference in the incidence of pre-existing concomitant diseases before spinal injury in our two groups: previous medical history did not seem to be related to the risk of development of HO.

In our patients with $\mathrm{HO}$, any pressure sores developed after $\mathrm{HO}$; such sores therefore are unlikely to cause heterotopic ossification. We also consider that thrombosis and embolism are secondary to $\mathrm{HO}$ rather than causative. Heterotopic ossification produces narrowing of the veins; this may be an important predisposing factor for thrombosis and embolism (Orzel, Rudd and Nelp 1984; Orzel and Rudd 1985). We found an increased number of urinary tract infections in our $\mathrm{HO}$ patients, as has been reported by others (Dejerine and Ceillier 1918; Damanski 1961), but there is no satisfactory explanation for this. Urinary and respiratory infections were seen both before and after the development of $\mathrm{HO}$, and both may contribute to its development by producing metabolic changes and release of inflammatory mediators.

Calcium mobilisation is a possible mechanism for the development of $\mathrm{HO}$ but, like other authors, we found no significant changes in serum calcium levels (Heilbrun and Kuhn 1947; Hossack and King 1967; Chantraine and Minaire 1981). The serum alkaline phosphatase level seems to be a more relevant guideline: this is manifest during the development of $\mathrm{HO}$, but the increase, not the absolute value, appears to be predictive (Furman,
Nicholas and Jivoff 1970; Nechwatal 1972; Chantraine and Minaire 1981; Bilow 1982). Chantraine and Minaire reported that alkaline phosphatase levels increased about three to four days after the first clinical symptoms of $\mathrm{HO}$ developed, between two and ten weeks after injury. Orzel and Rudd (1985) found an increase in alkaline phosphatase level before the development of clinical symptoms. Monitoring of the alkaline phosphatase therefore may be a reliable method of early detection and of control of treatment.

\section{Conclusions.}

1) The overall incidence of $\mathrm{HO}$ in our series of spinalcord injuries was $20 \%$.

2) Males $(23 \%)$ develop HO more than twice as often as females $(10 \%)$.

3) Patients with $\mathrm{HO}$ had predominantly cervical and mid-thoracic spinal injuries, while thoracolumbar and lumbar injuries were more common in the group without HO.

4) HO was found more often in tetraplegic patients and in those with motor lesions (Frankel A and B).

5) Urinary tract and respiratory infections, pressure sores and thrombo-embolism were significantly increased in patients with $\mathrm{HO}$.

6) The serum alkaline phosphatase level was significantly increased six weeks after the injury in patients with $\mathrm{HO}$ and may be a useful investigation for diagnosis and the control of management.

No benefits in any form have been received or will be received from a commercial party related directly or indirectly to the subject of this article.

\section{REFERENCES}

Bassett CAL. Current concepts of bone formation. J Bone Joint Surg [Am] 1962; 44-A; 1217-44.

Bilow KH. Spätkomplikationen bei Querschnittlähmungen und ihre Therapie. Unfallheilkunde 1982; 85:66-71.

Chantraine A, Minaire P. Para-osteo-arthropathies: a new theory and mode of treatment. Scand J Rehabil Med 1981; 13:31-7.

Coddington RC. Neurogenic ossifying fibromyositis in paraplegia: a case report. J Indiana State Med Assn 1961; 54:484-7.

Couvé LMJ. Heterotopic ossification and the surgical treatment of serious contractures. Paraplegia 1971; 19:89-93.

Damanski M. Heterotopic ossification in paraplegia. J Bone Joint Surg [Br] 1961 ; 43-B:286-99.

Dejerine M, Ceillier A. Para-ostéo-arthropathies des paraplégiques par lésions médullaires. Ann Méd Paris 1918; 5:497-535.

Furman R, Nicholas JJ, Jivoff L. Elevation of the serum alkaline phosphatase coincident with ectopic bone formation in paraplegic patients. J Bone Joint Surg [Am] 1970; 52-A :1131-7.

Garland DE, Alday B, Venos KG, Vogt JC. Diphosphonate treatment for heterotopic ossification in spinal cord injury patients. Clin Orthop 1983; 176:197-200.

Guttmann Sir L. Spinal cord injuries: comprehensive management \& research. Second edition. Oxford: Blackwell Scientific Publications, 1976:207-17.

Hardy AG, Dickson KW. Pathological ossification in traumatic paraplegia. J Bone Joint Surg [Br] 1963; 45-B:76-87.

Heilbrun N, Kuhn WG. Erosive bone lesions and soft-tissue ossifications associated with spinal cord injuries (paraplegia). Radiology 1947; 48:579-93.
Heller M, Ringe JD. Ungewöhnliche Lokalisation einer Paraosteoarthropathie (POA) an den Sternoklavikulargelenken. ROEFO $1979 ; 130: 114-5$.

Henderson HP, Reid DAC. Para-articular ossification in the hand Hand $1981 ; 13: 239-45$.

Hernandez AM, Forner JV, de la Fuente T, Gonzalez C, Miro R. The para-articular ossifications in our paraplegics and tetraplegics: a survey of 704 patients. Paraplegia 1978; 16:272-5.

Hossack DW, King A. Neurogenic heterotopic ossification. Med J Aust $1967 ; 1: 326-8$.

Knudsen L, Lundberg D, Ericsson G. Myositis ossificans circumscripta in para-/tetraplegics. Scand J Rheumatol 1982; $11: 27-31$

Major P, Resnick D, Greenway G. Heterotopic ossification in paraplegia: a possible disturbance of the paravertebral venous plexus. Radiology 1980; 136:797-9.

Nechwatal E. Die Vermeidung heterotoper Ossifikationen -ein zentrales Problem bei der Frühbehandlung von Querschnittgelhmten. Z Orthop 1972; 110:590-6.

Orzel JA, Rudd TG. Heterotopic bone formation: clinical, laboratory, and imaging correlation. J Nucl Med 1985; 26:125-32.

Orzel JA, Rudd TG, Nelp WB. Heterotopic bone formation (myositis ossificans) and lower-extremity swelling mimicking deep-venous disease. J Nucl Med 1984; 25:1105-7.

Scher AT. The incidence of ectopic bone formation in posttraumatic paraplegic patients of different racial groups. Paraplegia 1976 14:202-6.

Wharton GW. Heterotopic ossification. Clin Orthop 1975; $112: 142-9$.

Wharton GW, Morgan TH. Ankylosis in the paralyzed patient. J Bone Joint Surg [Am] 1970; 52-A:105-12. 